\title{
Developing a new business model for enabling research - the case of the ACPFG in Australia
}

\section{Stephanie C. Agius}

Australian Centre for Plant Functional Genomics

PMB1, Glen Osmond, South Australia, 5064, Australia

E-mail: stephanie.agius@acpfg.com.au

\section{David Corkindale}

International Graduate School of Business

University of South Australia

G.P.O. Box 2471 Adelaide, South Australia, 5001, Australia

E-mail: David.Corkindale@unisa.edu.au

\section{Antonio G. Dottore}

Education Centre for Innovation and Commercialisation University of Adelaide, South Australia, 5005, Australia

E-mail: antonio.dottore@ adelaide.edu.au

\section{Michael Gilbert*}

Australian Centre for Plant Functional Genomics PMB1, Glen Osmond, South Australia, 5064, Australia

E-mail: michael.gilbert@acpfg.com.au

*Corresponding author

\begin{abstract}
The way in which companies, research centres and educational institutions are organised and structured may provide a competitive advantage for commercialisation, in particular if companies are dependent on the deployment of complementary assets and capabilities by third parties.

This paper presents the case of the Australian Centre for Plant Functional Genomics (ACPFG), a private agricultural biotechnology (agbiotech) company specialising in early stage Research and Development (R\&D) to produce superior adapted cereal varieties, tolerant to abiotic stress conditions such as drought, frost, salt, or mineral toxicity, all of which have a direct and negative impact on plant growth and crop productivity.

The organisational structure of the company has been influenced and shaped by Government policy, shareholders expectations and trends in the agbiotech industrial organisation. It has proved attractive to potential alliance partners for collaborative R\&D and commercialisation.

We present the ACPFG as a new business model to fund basic research and facilitate technology transfer.
\end{abstract}

Keywords: Australian Centre for Plant Functional Genomics (ACPFG); agricultural biotechnology (agbiotech); commercialisation; industry consolidation; intellectual property; transaction costs; strategic alliance; licensing; technology transfer; complementary assets; core competences. 
Reference to this paper should be made as follows: Agius, S.C., Corkindale, D., Dottore, A.G. and Gilbert, M. (2006) 'Developing a new business model for enabling research - the case of the ACPFG in Australia', Int. J. Technology Intelligence and Planning, Vol. 2, No. 2, pp.117-128.

Biographical notes: Stephanie C. Agius is Commercialisation Officer at the Australian Centre for Plant Functional Genomics. She has a PhD degree in Plant Mitochondrial Physiology from the University of Lund, Sweden and a Masters of Science and Technology Commercialisation degree from the University of Adelaide. Her major interests are commercial strategy for agricultural biotechnology and intellectual property management.

David Corkindale is Professor of Marketing at the University of South Australia. He obtained his $\mathrm{PhD}$ in Marketing and Master of Science in Operational Research at the Cranfield School of Management, England. His main research interests are the commercialisation and marketing of new technologies; the adoption and diffusion of innovations and of new technology, upon which he has taught and published.

Antonio G. Dottore is Director of the Education Centre for Innovation and Commercialisation at the University of Adelaide. He has an MBA from INSEAD, France, and an Economics degree from Flinders University, Australia. His main interests are in strategic management and decision-making of firms.

Michael Gilbert is General Manager and Company Secretary of the Australian Centre for Plant Functional Genomics. He graduated with a Mechanical Engineering degree in 1984 and an MBA from the University of Adelaide in 1998. He is interested in applying established business principles to maximise relevance of research outcomes in a changing environment.

\section{Introduction}

Turning innovations into commercial success has been identified as being key to Australia's future prosperity (Commonwealth of Australia, 2001). During 1999, the Australian Research Council (ARC), an Australian Government investment body to foster excellence and partnerships in research in all fields of science and the Grains Research and Development Corporation (GRDC), a world leading grains research funder, sponsored workshops to explore new opportunities in agricultural genomics. The aim was to identify a research opportunity which would have mutual benefits to the ARC and the GRDC. The Australian Centre for Plant Functional Genomics (ACPFG) presented a research and business opportunity to both parties.

The ACPFG is a new research centre with a commercial focus funded by a number of government and semi-government bodies. Its key imperative is to conduct high quality genetic research to develop superior adapted cereal varieties tolerant to abiotic stress conditions such as drought, frost, salt, or mineral toxicity, all of which have a direct and negative impact on plant growth and crop productivity.

Prior to the establishment of ACPFG, it was recognised that commercialisation of technology within a conventional research structure may be difficult due to a variety of issues including organisational structure, culture and ownership of Intellectual Property 
Rights and prioritising commercial applications of R\&D. Conventional research structures have excellent research as their core competence but the application of innovations may be a secondary consideration.

For ACPFG, investment opportunities were also important considerations. The 2001 Organisation for Economic Cooperation and Development (OECD) study on R\&D Productivity Growth (Guellec and van Pottelsberghe de la Potterie, 2001) showed that whilst an increase in $1 \%$ of business expenditure generates an additional $0.13 \%$ increase in productivity growth, foreign business investment generates a $0.44 \%$ increase. The task was therefore to establish ACPFG as a world-class research establishment but with a structure that would facilitate commercialisation of technological innovation and the ability to leverage government and private sector funds, infrastructure and know-how in particular, from foreign sources. Given the large number of possible structures to choose from, which structure would be the most likely to lead to commercial success? The funders of ACPFG decided to adopt a private industry model so that it could capture leverage opportunities and maximise the likelihood of commercial success.

\section{Shareholders}

All shareholders wanted to establish a world-class research centre in the area of plant functional genomics. The desired outcomes of the cash funders of ACPFG varied. One funder required internationally recognised research as evidenced through a series of criteria including publications and, whilst commercial application of that research was important, it was not its primary aim. On the other hand, the farmer funded body wanted positive outcomes for Australian farmers as it provides money for research where the horizon for commercial return is too far away for funding by commercial companies. Another funder desired local employment and increased economic activity within the local region.

The key problem was to develop a structure that would address each shareholder's requirements. A working group was established in 2002 to establish ACPFG and a project manager was appointed.

\section{Shareholding}

Once all shareholders agreed the ACPFG would be established, a mechanism was introduced to ensure shareholding in the company reflected actual contributions. Importantly, as company equity was the only means of shareholders influencing the strategic direction of ACPFG, equity holdings in ACPFG needed to be accurate.

A model was developed by which shareholdings were valued. It was decided that initially, 100 shares would be issued in the company. Each participant was issued an initial allocation of shares in proportion to their envisaged project inputs. These inputs were calculated looking forward five years and both cash and in-kind inputs were taken into account and given equal status. An adjustment mechanism was also devised whereby, in future years, further shares would be issued in proportion to the actual contributions made. Hence at the end of any year, shareholding should remain in proportion to the contributions from respective shareholders.

ACPFG was finally incorporated as a company limited by shares in November 2002. 


\section{People resources}

ACPFG's management structure is designed to identify, capture and commercialise innovation within a research environment. An experienced professional board governs the company where directors were chosen for their expertise and experience in research, commercial, or market skills (Figure 1).

Figure 1 Organisational structure of the ACPFG

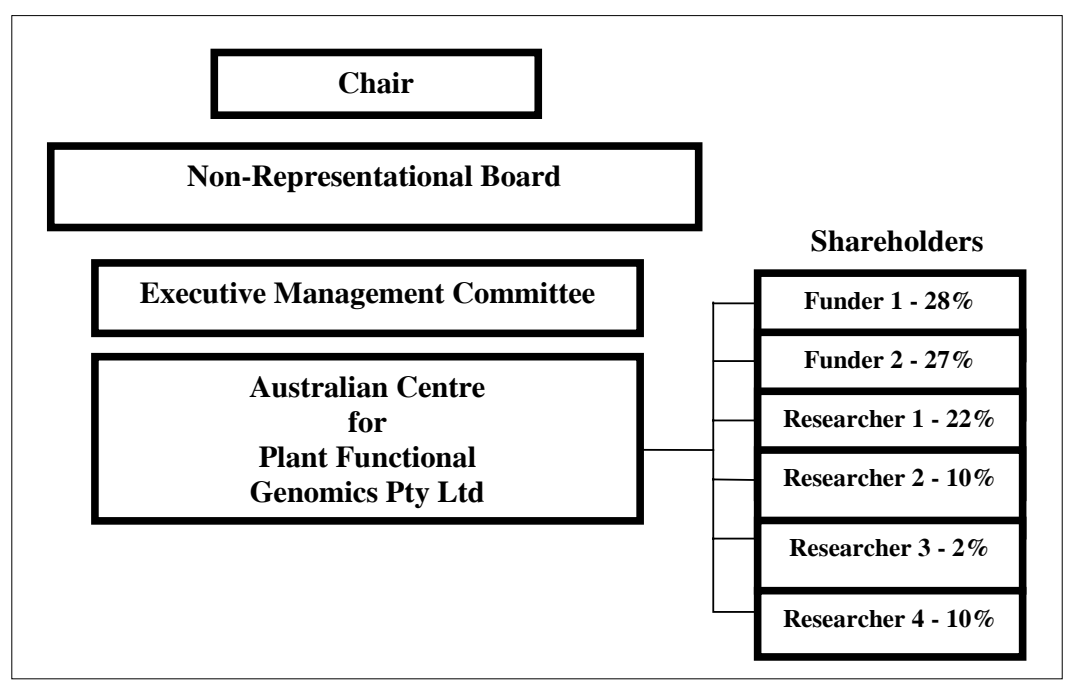

The Board is not representational of individual shareholders; the members are chosen jointly by the shareholders for their skills rather than to represent the interests of particular shareholders. This ensures the Board acts in the best interests of the company. An Executive Management Committee is responsible for overseeing projects and monitoring progress of research, and IP and commercialisation skills are used to support the Chief Executive Officer's (CEO) role of decision-making and strategic direction of the company.

The original shareholders' objective to develop the company's core competence in the discipline of plant functional genomics, favoured the appointment of a CEO experienced in research management and training, rather than commercialisation of agbiotech. An internationally renowned scientist of high calibre with extensive research and industry networks was chosen as the preferred leader for the company. By focusing on recognised agronomic problems, the CEO could provide the research direction required for development of commercial solutions applicable to a global market. In addition, this choice of leadership was intended to facilitate the transition from a university and research publication culture, to a commercially orientated R\&D company as the majority of scientific personnel were university employees seconded to a private company.

ACPFG's roots lie in public sector research. The task of converting it to a commercial ethos presents the challenges described in Schein (1996). Schein's (1996) 'Operator Culture' is reflected accurately in ACPFG's international team of scientists. It is a complex, flexible network relying on communication, trust and teamwork to bring 
projects to fruition. Partly due to its flat hierarchical structure, ACPFG is a long way from having an 'Executive Culture' more usual in commercial organisations. Typically in the Executive Culture the CEO is preoccupied with finances and views human resources as a cost rather than a capital investment. In ACPFG, the CEO has not adopted an exclusive financial viewpoint. Instead, he plays a pivotal role in the company's R\&D direction by maintaining an active research programme and views the company's key resource as scientific personnel.

To bridge the gap between Stein's three stated cultures, staff members who combine engineering or scientific backgrounds with business and commercialisation qualifications and experience support the CEO's vision. The resultant hybrid Operator/Executive culture, places a greater emphasis on developing a system of quality control whereby personnel are governed by an independent board which in turn is accountable to the company's shareholders. This is a structure that the commercial world understands and is familiar with.

\section{Intellectual Property (IP)}

Intellectual Property (IP) agency agreements contract a number of Australian universities to carry out R\&D on behalf of ACPFG. These agencies are also ACPFG shareholders. As each research programme develops IP, that IP vests immediately in ACFPG (Figure 2). This is a key element of the commercialisation strategy.

Figure 2 IP ownership

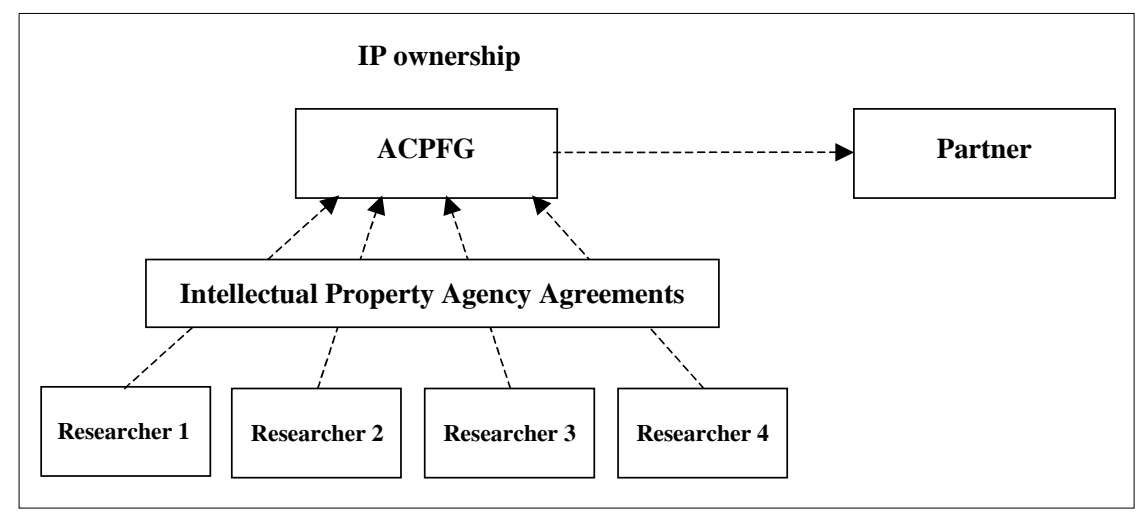

The company has the ability to sell or out-license any technology as ACPFG owns all IP arising from the programme as developed from the four interdependent research nodes (Figure 2). Unconstrained IP dealings, and having only one entity to deal with, has proved attractive for third parties to consider ACPFG as a potential commercial partner. This is evidenced by the number and quality of commercial organisations now in dialogue with ACPFG.

ACPFG is forming long-term relationships for collaborative $R \& D$ and commercialisation. Industry dynamics and its own capability portfolio were significant determinants in identifying partners. ACPFG relies on its core competence and location in an internationally renowned agri-food cluster, the South Australian Waite Precinct, to 
develop 'strategic architecture' (Prahalad and Hamel, 1990). Being able to identify which core competencies to develop, and their constituent technologies, has prioritised company resources to focus on early stage technologies.

Proprietary technologies are used as a competitive tool to leverage negotiations and can provide major agbiotech companies with a competitive advantage to expand market potential through collaborative $R \& D$ and commercial licensing agreements. Out-licensing the technology to third parties to form a long-term 'strategic' alliance for collaborative R\&D, and commercialisation is a preferred strategy due to the long lead-time for product development and limited life of patent protection. Close collaboration with organisations can significantly reduce the time to market for new products.

The platform nature of ACPFG technology affords several licensing options, which suit the company's financial and non-financial objectives. ACPFG has decided to out-license its technology, based upon application by crops, with no geographic limitation. Thus, monetary returns will be had from licensing into the global market, faster development is achieved via collaboration with much larger organisations and technologies can also diffuse into local industry.

Out-licensing technology should also contribute to maintaining a steady cashflow. This decreases the reliance on public sector funding and leaves open the option of using the technology in new ways for different applications, not yet discovered.

Another reason for out-licensing IP to large agbiotech companies is that the technology can be bundled together to create synergies with other product features. These 'stacked traits' can provide greater returns on investment than if ACPFG attempted to market its IP in isolation.

The other option available is sale of the IP, however this divests the centre of any control over its development and diffusion into the Australian grains industry. This would be undesirable for one of its major shareholders.

A corollary of the agency agreement provisions is that discretion over publication of results lies with ACPFG. This has not been a disadvantage to knowledge dissemination. In fact, during its short-life span, ACPFG has contributed to expanding public knowledge through:

- over 120 publications in refereed journals

- more than 70 presentations to international conferences

- numerous workshops and conferences organised by ACPFG

- an extensive community education programme.

\section{Commercialisation}

Structure, staffing and ongoing management of ACPFG have revolved around developing $R \& D$ core competences in the agbiotech supply chain. Its organisational culture also reflects this. Translating core competencies and organisational culture into successful commercialisation, while meeting the varied objectives of its shareholders, is predicated upon actions that bring to bear Kay's (1993) conclusion: 


\begin{abstract}
"Corporate success derives from a competitive advantage, which is based on distinctive capabilities, which is most often derived from the unique character of a firm's relationships with its suppliers, customers, or employees, and which is precisely identified and applied to relevant markets."
\end{abstract}

\title{
7 Commercially focused
}

ACPFG is funded to develop abiotic stress tolerance in wheat and barley crops. It is unlikely it could become self-funding based on commercialisation of wheat and barley research outcomes in Australia alone. It will therefore be important to secure a dividend from any improvements made to major commercial crops in other regions. Revenues from such international exploitation of ACPFG outcomes would provide cash for developing further outcomes aimed primarily at Australian farmers but secondarily for crops in other markets.

ACPFG's outcomes may have application to crops for which a well-developed and valuable market exists for new varieties and where models for margin capture are well-defined.

The obvious choices of alternative market targets are the maize market in the USA and the rice market in the USA and Asia. Maize and rice are also cereals and genomics solutions developed in wheat and barley have a good chance of success in these crops due to phylogenic similarities. The maize crop in the USA is over 14 times as large as the Australian wheat crop and there are opportunities for ACPFG to transfer its knowledge in wheat and barley into maize (USDA, 2005). Europe is not being considered at present due to regulatory and consumer related impediments but it does represent a very large potential market.

It is also unrealistic to expect that the centre has, or could easily develop, the requisite capabilities to engage in full commercialisation on its own. Due to trends in industry structure and transaction risks mentioned below, ACPFG is seeking to commercialise its technologies through licences, where the licensee is also effectively a strategic partner rather than an arms-length counter party. This leverages the centre's capabilities and affords the partner a form of outsourced innovation that is linked to its own system, while retaining flexibility for the respective parties to pursue their own objectives.

In fact, 'prior related knowledge' can be a critical resource for a company attempting to commercialise a new technology and an important reason why firms with similar and overlapping capabilities collaborate with each other (Davenport and Miller, 2000).

\section{External agbiotech market}

As has been explained earlier, the ACPFG needs to gain income from commercialisation of IP it develops in order to help fund the aims and objectives of its various stakeholders. It is initially developing IP that has application to specific sectors of the seed industry. Those organisations that are major players in the seed industry are, therefore, the potential commercialisation agent of ACPFG's IP (Figure 3). Who are they? How strong is their bargaining position? What is happening in their industry - how profitable is it? What are their interests, both now and in the future? These are questions that must be considered when the commercialisation strategy for ACPFG is developed. 
Figure 3 Flowchart of delivery of product to market

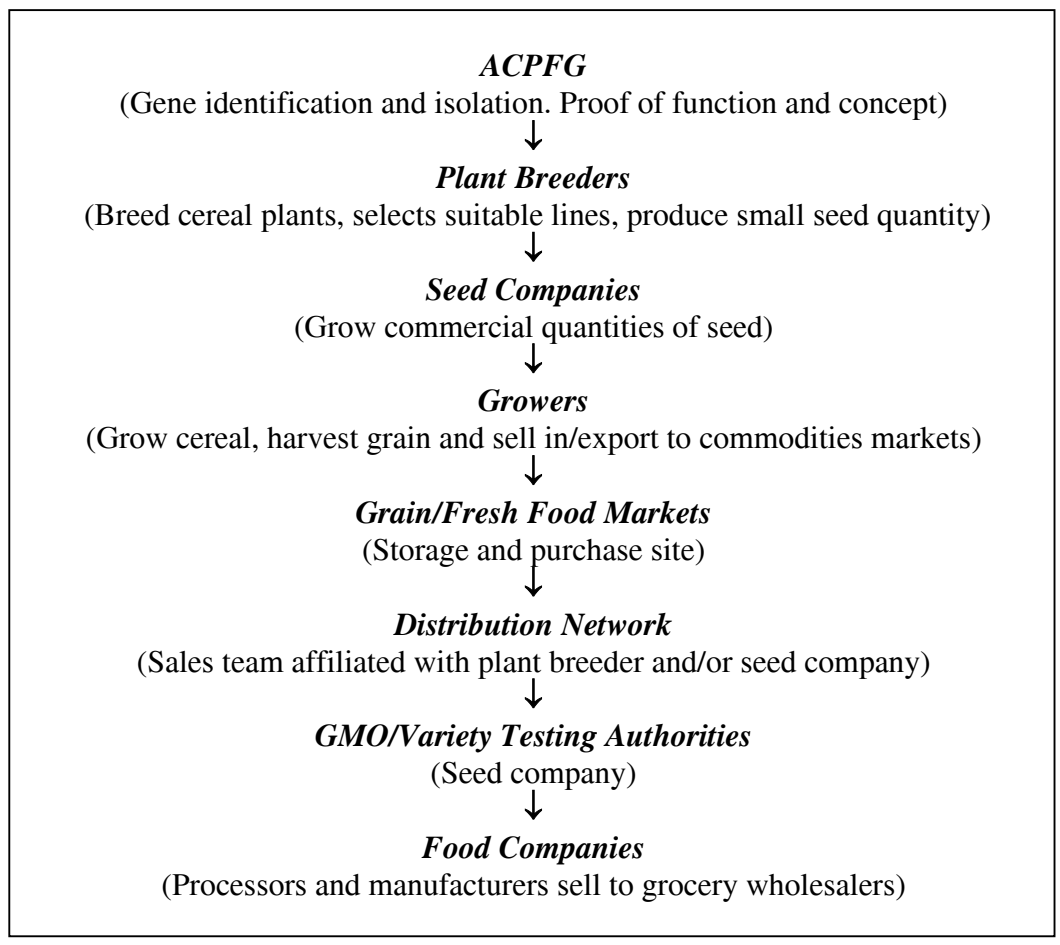

Note: Agbiotech companies usually have acquired plant breeding and crop seed companies

\section{Agricultural industry consolidation}

The agricultural production industry has been impacted by the emergence of biotechnology during the last 20 years and major restructuring has occurred because of it. Initially several large chemical firms including Monsanto, Dow and DuPont moved into plant biotechnology to create agronomic systems companies. They acquired the seemingly successful agbiotech research companies and large national seed companies in the USA to create vertically integrated firms capable of discovering and commercialising innovations in agricultural technology.

This industry consolidation happened very rapidly and was notable for the high prices paid for both research and seed firms, by the chemical companies. The industry is also now characterised by a web of alliances that span basic R\&D through to marketing and is also highly concentrated.

By 1998, the top five 'gene' companies (AstraZeneca, DuPont, Monsanto, Novartis and Aventis) accounted for nearly two-thirds of the global pesticides market, almost one quarter of the commercial seed market and virtually all of the transgenic seed market. Additionally, the top ten seed companies controlled around 23\% of the $\$ 23$ billion worldwide seed trade with the top three companies (DuPont, Monsanto and Novartis) having around a 20\% share (Johnson and Melkonyan, 2003). 


\section{The benefits of consolidation of the industry}

The change in the structure of the agricultural inputs industry is suggested to be a response to the new opportunity for tailoring the genetic makeup of crops. To capitalise on this, a firm needs an array of specialised capabilities in plant genetics: tools for plant genetic transformation, genes and elite crop germplasm, all of which have been patentable in the US, and other western markets, since the 1980s. These intellectual assets complement one another for a particular crop: more of one will lead to an increase in the value of the other two (Graff et al., 2003). There is, therefore, an incentive for firms to gain access to all three which is possible through in-licensing or buying technologies. However, if the transaction costs are high or not straightforward, it is simpler just to acquire them and consolidate them into one organisation.

The structure of the agbiotech industry has evolved differently than other research-intensive ones (Graff et al., 2003). The pharmaceutical biotech industry, for example, has had a large number of individual firms that specialised in R\&D and earned their revenue through various licensing arrangements (Majewski, 1998). The US semiconductor industry has evolved in an opposite way with there being a substantial disaggregation and new firms have appeared that specialise in the intellectual process of chip design and who outsource the manufacturing and other commercialisation processes (Hall and Ziedonis, 2001).

\section{The theory of asset complementarities}

A further explanation of the benefits of consolidation of the industry is given by the Theory of Asset Complementarities where intellectual assets are intentionally managed and coordinated (Teece, 1986). When owners of different assets, like IP, manage their (research) outputs independently of one another without taking into account the synergistic effects that their production has on the holders of other, complementary assets, the total potential value of the assets, both private and social, may not be realised. This is particularly true in times of rapid technological change, where R\&D investment is high and where the development of industries and markets is seen as complex and uncertain (Milgrom and Roberts, 1990). One response to this situation is to arrange that all assets are subject to one management regime, that is, in a single firm. However, this is not the only solution and there are downsides. As a firm grows in size, it must increasingly manage transactions between internal assets and this leads to increasing bureaucracy and cost. The alternative of managing external transactions between assets is inherently problematic, too.

Graff et al. (2003) use the Theory of Asset Complementarities to seek to explain firm boundaries and industry consolidation in the agricultural biotech industry. Their findings support the hypothesis that the industry's restructuring and concentration over the past 20 years has been causally driven by the attempt by major firms to achieve coordination between complementary intellectual assets. 


\section{Other explanations}

There are yet other reasons why consolidation of the agbiotech industry has happened such as the erection of barriers to entry, achieving market power, achieving economies of scale in R\&D and access to global markets. However, Graff et al. (2003) assert that none of these reasons by themselves would have generated the concentration of IP holdings and of the industry.

Johnson and Melkonyan (2003) examine the apparent motivations for the consolidation and resulting concentration in the agricultural biotech industry. They studied the history and behaviour of four of the major players in the industry: DuPont, Monsanto, Novartis and Dow Agrosciences. They developed a model which appears to explain well the consolidation patterns in the biotech industry; "the key results derive from the benefits of coordinated actions, distinction between transferable and non-transferable payoffs and the substitutability, complementarity and the importance of managers' non-contractible investments". It was observed that with the exception of Dow Chemical, which did not have a pharmaceutical business, the acquisitions by these big firms anticipated the creation of value or synergies between pharmaceutical and agricultural businesses. However, this interdependence and synergy did not materialise. The two companies with the biggest pharmaceutical businesses made decisions to either spin these off as separate activities or to divest them. All four firms seem to support consolidation as a means of gaining market access and substitutability. Market expansion has been achieved by acquiring firms that were already well established in desirable markets.

\section{Business realities}

At the turn of the century, Monsanto was arguably the world's most controversial company, praised by those who saw a future of environmentally friendly farming and healthier diets via high-tech crops, and damned by others who considered them promoters of ecological destruction and corporate control of the global food supply. Under siege from anti-GM protestors and heavily indebted after its $\$ 5.3$ billion acquisition spree, Monsanto was bought by Pharmacia, US drug company, for its successful pharmaceutical division, Searle.

In 2000, Pharmacia floated $15 \%$ of Monsanto on the stock market and announced plans to spin-off the rest by the end of that year. In 2002, Pharmacia itself was bought by Pfizer, a US rival and the Monsanto sale was enacted. This caused Monsanto to become a different entity. In 2000, Hendrik Verfaillie replaced Robert Shapiro as CEO, who had formulated the strategy of focusing on the 'life sciences' and the synergies from combining farming, food and pharmaceuticals, as described earlier. Not only did Monsanto lose its drug-making arm but it also shed its profitable NutraSweet business. Within agriculture, it narrowed its interest to four key crops: soybeans, maize, wheat and cotton (Economist, 2002). 
Pharmacia gave the firm much-needed breathing space, assuming most of its debt and leaving it to get on with cutting costs and integrating the many seed companies that it bought in the late 1990s. Rivals such as DuPont had also to cut costs in order to meet profit-margin targets. This was particularly true in the crop-protection business as global sales of chemical pesticides were expected to shrink by more than $10 \%$ to $\$ 11.8$ billion by 2004 .

The agrochemical and seed industry is under pressure on several fronts, including persistently low commodity prices and industry consolidation. The second of these has created bigger competitors in crop chemicals. Another factor is the economic problems of Argentina, a big consumer of chemicals. Although crop chemicals still accounted for almost $70 \%$ of Monsanto's revenues, their prospects were dimming because the firm's best-selling herbicide, called Roundup, went off-patent. Monsanto saw its future in innovative seeds and genomics. The firm was backing this with money: in 2001, $83 \%$ of Monsanto's \$550 million investment in research and development went into seeds and biotechnology, compared with an industry average of $29 \%$ (Economist, 2002).

An analysis of the industry that does R\&D for the seed industry, using Porter's (1988) five-forces model would suggest that the 'buyers', in this case the large seed companies, are very powerful. It would also suggest that this industry will be competitive and not highly profitable.

\section{What does this all mean for the ACPFG's commercialisation strategy?}

For a variety of reasons as described above, the route to major markets for the commercial application of ACPFG's initial, intended IP will have to be through major agbiotech seed firms. These are in a strong position and needing to extract sufficient profits to pay-off the large investment required in research. In addition, as many key technologies are owned by dominant US agbiotech companies and there is competition to patent genes for future products, companies and public sector institutions are partnering to coordinate R\&D strategy with merger and acquisition strategy, to access complementary intellectual assets and decrease transactions costs (Graff et al., 2003).

Additionally, the degree to which IP transfer arrangements allow the ACPFG to benefit from research conducted by other agbiotech companies, or its agents, will have an impact on the ways in which the ACPFG can benefit its stakeholders. All of these considerations in the choice of commercialisation route and possible partners have implications for the way the ACPFG is structured and managed. The overall strategy for the development of the ACPFG must allow for these considerations.

\section{Conclusion}

The ACPFG was created in an environment where public sector funding for research activities is increasingly difficult to secure, and there is increasing pressure on universities to secure 'third stream' funding through commercialisation. Further, there is strong evidence that the wide cultural and operational divide between research and market-driven organisations remains an impediment to science and technology commercialisation. 
ACPFG represents a new business model to fund basic research and facilitate technology transfer into the world market. It brings together its shareholders' multiple objectives: financial and non-financial. The embodiment of the business model is seen in the company's organisational structure, single ownership of IP, business and commercial strategies, in addition to staffing considerations to enable various desired outcomes from the R\&D programmes to be achieved.

The ACPFG has been established to foster excellence in plant genomics and commercialise its research outcomes. By developing core competence, ACPFG can capture leverage business opportunities via a private industry model to maximise the likelihood of commercial success and become partially self-funding through commercialisation of proprietary IP.

\section{References}

Commonwealth of Australia (2001) Backing Australia's Ability: The Commonwealth Government's Commitment to Innovation, http://www.backingaus.innovation.gov.au/.

Davenport, S. and Miller, A. (2000) 'The formation and evolution of international research alliances in emergent technologies: research issues', J. High Tech. Management Research, Vol. 11, pp.199-213.

Economist Magazine (2002) 'Genetically modified company', The Economist, Vol. 374, No. 8340, pp.54-55.

Graff, G.D., Rausser, G.C. and Small, A.A. (2003) 'Agricultural biotechnology's complementary intellectual assets', The Review of Economics and Statistics, Vol. 85, No. 2, pp.349-363.

Guellec, D. and van Pottelsberghe de la Potterie, B. (2001) R\&D and Productivity Growth: The Panel Analysis of 16 OECD Countries, http://ideas.repec.org/p/oec/stiaaa/2001-3-en.html.

Hall, B.H. and Ziedonis, R.H. (2001) 'The patent paradox revisited: an empirical study of patenting in the US semiconductor industry, 1979-1995', RAND Journal of Economics, Vol. 32, No. 1, pp.101-128.

Johnson, S.R. and Melkonyan, T.A. (2003) 'Strategic behaviour and consolidation in the agricultural biotechnology industry', American Journal of Agricultural Economics, Vol. 85, No. 1, pp.216-233.

Kay, J. (1993) Foundations of Corporate Success, Oxford: Oxford University Press.

Majewski, S.E. (1998) 'Causes and consequences of strategic alliance formation: the case of biotechnology', University of California-Berkeley PhD Dissertation.

Milgrom, P. and Roberts, J. (1990) 'The economics of modern manufacturing: technology, strategy and organisation', American Economic Review, Vol. 80, pp.511-528.

Porter, M.E. (1988) Competitive Strategy; Techniques for Analyzing Industries and Competitors, New York: The Free Press.

Prahalad, C.K. and Hamel, G. (1990) 'The core competence of the corporation', Harvard Business Review, May-June, pp.79-91.

Schein, E.H. (1996) 'Three cultures of management: the key to organizational learning', Sloan Management Review, Vol. 38, No. 1, pp.9-20.

Teece, D.J. (1986) 'Profiting from technological innovation: implications for integration, collaboration, licensing and public policy', Research Policy, Vol. 15, pp.285-305.

United States Department of Agriculture (USDA) (2005) World Agricultural Production, http://www.fas.usda.gov/wap/circular/2005/05-09/Wap\%2009-05.pdf. 